\title{
Outcome analyses of a multimodal treatment approach for deep pressure ulcers in spinal cord injuries: a retrospective cohort study
}

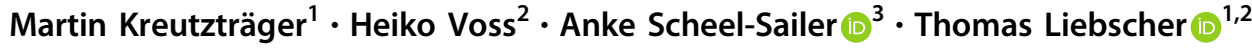

Received: 12 March 2017 / Revised: 4 January 2018 / Accepted: 6 January 2018 / Published online: 31 January 2018

(c) International Spinal Cord Society 2018

\begin{abstract}
Study design Retrospective observational cohort study.

Objectives To describe outcomes, risk factors for complications, and relapse rates associated with the multimodal treatment approach for deep pressure ulcers (PUs) grade IV for the ischium, trochanter major, and sacral regions of patients with traumatic and non-traumatic spinal cord injury (SCI).

Setting The settings comprised two spinal cord units within a maximum care hospital. The treatment of all patients followed the modified interdisciplinary "Basler treatment concept".

Methods We included all individuals with SCI with a first occurrence of PU grade IV in the buttocks area between August 2008 and December 2012 inclusive, with a maximum follow-up of 3 years. Descriptive, univariate, and bivariate analyses were undertaken, as were group comparisons.

Results In 47 patients aged 18-87 years (mean age: 51 years) a total of 63 fasciocutaneous and myocutaneous flaps were performed. Wound healing was complete after a mean of 34 days $(\mathrm{SD}=21)$. Postoperative mobilisation in a wheelchair was performed after a mean of 46 days $(\mathrm{SD}=24)$. Delayed healing was reported in 18 patients $(38 \%)$, and revision surgery was necessary in five patients (11\%). ASIA impairment scale (AIS) A $(p=.001)$, and male gender $(p=.001)$ were identified as risk factors for delayed wound healing and prolonged inpatient stay.

Treatment-associated pneumonia occurred in four cases (11\% of all patients, $25 \%$ of patients with tetraplegia). Patients were discharged when the time spent sitting in a wheelchair was $2 \times 2 \mathrm{~h}$ per day; this occurred after a mean of 100 days $(\mathrm{SD}=36)$. PU recurrence was observed in six cases $(18 \%)$.

Conclusions Our multimodal treatment concept was found to have complication rates comparable to those in the literature; additionally, this approach might be associated with lower recurrence rates with respect to the literature. To reduce high rates of pneumonia occurrence among patients with tetraplegia, preventive measures need to be established. Further evidence of the efficiency of this complex treatment approach for PU in individuals with SCI is needed.
\end{abstract}

\section{Introduction}

Treatment concepts for deep pressure ulcers (PUs) in patients with a spinal cord injury (SCI) continue to be widely discussed, given the high complication and relapse

Martin Kreutzträger

Martin.kreutztraeger@ukb.de

1 Treatment Centre for Spinal Cord Injuries, Trauma Hospital Berlin, Berlin, Germany

2 SRH Klinikum Karlsbad-Langensteinbach, Handchirurgie und Plastische Chirurgie, Karlsbad, Germany

3 Swiss Paraplegic Centre (SPC), Nottwil, Switzerland rates involved $[1,2]$. To achieve higher-quality results when treating this common complication in people with SCI [3, 4], lesions have been classified by using the European (National) Pressure Ulcer Advisory Panel (NPUAP/ EPUAP) guidelines, along four grades [5]. At grade III, a total loss of all skin layers occurs; at grade IV, tendons, bones, or muscles are visible [6]. Ulcers occur due to pressure-induced damage to exposed tissue layers, resulting from reduced perfusion and the occurrence of necrosis [7].

Given improvements in the treatment and care of individuals with SCI and the associated higher life expectancy, an increase in the incidence rate of paralysis-associated ulcers is expected $[8,9]$. In all, $85 \%$ of all people with SCI develop a PU during their lifetime [10]. Conservative treatment commonly is used for PUs classified as grades 
I-III [3, 11, 12], whereas grade IV lesions require an operative approach that features debridement and secondary closure $[1,2,4,12,13]$. Prior to the introduction of plastic surgical lap-flaps in the 1980s, operative procedures were associated with a high number of complication rates and failed closure [14, 15]. The current standards for the plastic surgical treatment of grades III and IV PUs in the regions of the sacrum [16, 17], the ischium [18, 19], and the trochanter major $[20,21]$ are defined by the use of local flaps $[1,2]$.

In addition to the development of surgical procedures, risk factors pertaining to PU development have been integrated into the secondary preventive measures of comprehensive treatment concepts [22, 23]. With the development of multimodal treatment approaches, complication and recurrence rates have been reduced by $20-30 \%[1,2,11]$. Given the heterogeneity of the patient population and the variety of therapies used, the efficacy of various treatment components remains unclear. PUs are often associated with osteomyelitis and sepsis, and different medication concepts are applied [10]. Nutritional deficiencies are known and are addressed in different ways, and long periods of immobilisation and prolonged hospitalisation can lead to elevated psychological distress.

The aim of this study is to analyse treatment characteristics and describe the incidence rate of treatment-associated complications, both with respect to an established complex treatment concept for deep PUs in the buttocks region of patients with SCI. Furthermore, this study identifies the risk factors for postoperative impaired wound healing, bearing in mind the duration of inpatient treatment and lesion recurrence.

\section{Methods}

A modified comprehensive treatment approach was derived from the "Basler decubitus concept" [2, 24], as implemented by the author (TL) in two specialised spinal cord units (Trauma Hospital Berlin and SHR Klinikum KarlsbadLangensteinbach) with appropriate settings. It consists of predefined algorithms pertaining to pressure relief, wound conditioning, malnutrition substitution, plastic surgical treatment, antibiotic therapy, and specialised nurses. The plastic surgical treatment procedures were only performed by the two authors (TL and HV). We included all patients admitted between August 2008 and December 2012 with a PU grade IV; in all cases, a follow-up had been performed within 3 years of discharge in an outpatient consultation. The ethics committee of the Charite approved the study protocols (EA2/015/15), and the study itself was carried out in compliance with Declaration of Helsinki criteria.

\section{Participants}

All patients analysed were aged $\geq 18$ years and had sustained a traumatic or non-traumatic SCI (ASIA impairment scale (AIS) A-D). No individuals with multiple sclerosis were included. Inclusion criteria were at least one PU grade IV as per the EPUAP classification [6], in the sacral, ischial, or trochanter major region. We did not differ between the sacral and coccyx regions. We defined a previous operative approach in the same area as an exclusion criterion to ensure a standardised surgical procedure for the plastic surgery.

\section{Intervention}

Integrated in the "Basler treatment concept" are conservative and operative professions, health care, and ongoing patient education [24-26]. Six interdisciplinary principles were defined and specially adapted to the needs of individuals with traumatic or non-traumatic SCI.

Nursing care was standardised for patients with SCI, so that nurses could perform correct positioning techniques and intervals, and were sufficiently skilled in urinary bladder and bowel management.

\section{Pressure relief}

After admission to the hospital, a consistent and permanent pressure relief was performed by changing the patient's position every $3-4 \mathrm{~h}$ during the day and night. Special mattresses were selected in accordance with skin condition in the pressure-exposed areas. If sufficient pressure relief was not achievable (i.e., in case of multiple ulcers), an air fluidised therapy bed was used.

\section{Operative debridement and infection control}

Every debridement was performed in the operating room, to ensure an aseptic setting and reduce the risk of uncontrolled bleeding.

At hospital admission, wound swabs were performed to identify the bacterial spectrum and the resistogram. Our approach included antibiotic treatment based on the resistance test results. Treatment was administered for the first time with a plastic surgical closure. In each case, a systemic oral or parenteral antibiotic treatment was administered for 14 days based on the resistogram.

Besides the mentioned concept for the surgical closure, systemic antibiotic treatment prior to surgical closure was administered only if sepsis occurred, in line with the criteria of the Centers for Disease Control and Prevention (CDC) [27]. A septic state (temperature $\geq 38.5^{\circ} \mathrm{C}$; leukocytosis $\geq$ 
Fig. 1 Standardised plastic surgical operation procedures plastic surgical management

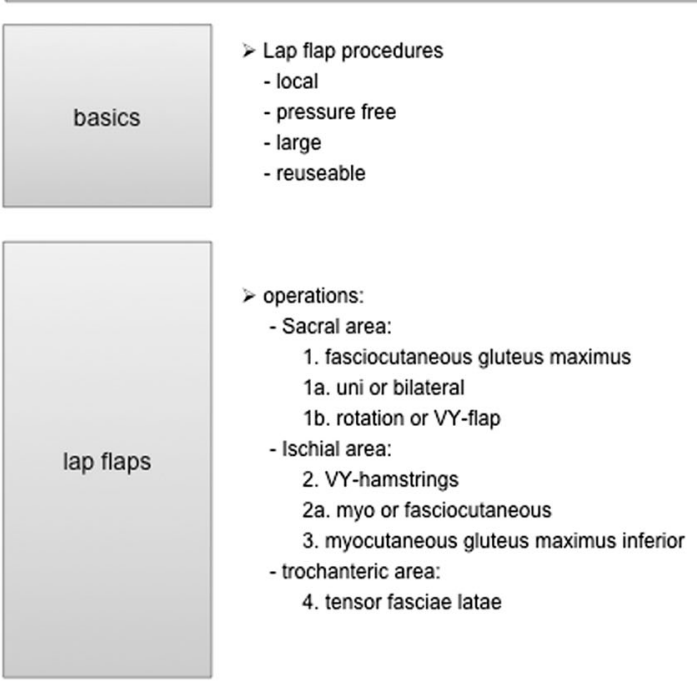

$12,000 / \mu \mathrm{l}$; positive blood cultures) was treated early with antibiotics, upon admission.

\section{Wound conditioning}

Wound conditioning was performed either in an open manner (with wound irrigation and treatment with Lavanid ${ }^{\circledR}$ (Serag-Wiessner, Naila, Germany)) twice daily, or with negative pressure wound dressings $\left(\mathrm{VAC}^{\circledR}\right.$, KCI, Wiesbaden, Germany) that were applied in the operating room at 3day intervals.

\section{Treatment of risk factors and nutritional optimisation}

Substitutions were made for abnormal sodium and potassium levels. Erythrocyte concentrates were administered whenever the haemoglobin value was $<5.0 \mathrm{mmol} / \mathrm{l}$. Screening for malnutrition was performed upon admission, using nutritional risk screening (NRS) [28]. For each patient, a nutrition plan was created, and Fresubin ${ }^{\circledR}$ Energy drinks (Fresenius Kabi, Bad Homburg, Germany) were offered twice daily if a patient's NRS score was $\geq 3$ points.

\section{Plastic surgery as closing procedure}

All PUs were closed using standardised plastic surgical operation procedures (see Fig. 1). Two experienced surgeons performed all local myocutaneous and fasciocutaneous rotation, transposition, or VY flaps. "VY" is a special cutting technique, where a "V"-shaped cut is transformed into a "Y"-shaped flap. Large flaps were selected, given the lifelong pressure that would be exerted when sitting in a wheelchair and when performing transfers, so that further operations using the same flaps would be possible. A flap closure needs to be tension free, to allow for spasticity and the lack of muscular stability in the hip joints. Redon drains were placed in the appropriate wound compartments, and they were removed when the delivery volume was $<10 \mathrm{ml}$ in $24 \mathrm{~h}$. Pressure relief of the surgical area was conducted postoperatively until complete wound healing, after a minimum of 21 days. We performed prone positioning, to perform pressure relief and to avoid hip flexion. If there was a high degree of spasticity leading to hip flexion, the leg was mechanically fixed in a hip extension position. During that time, patients required bed rest, and mobilisation was performed for the upper extremities and for nonsurgically treated lower extremities. Additionally, respiratory therapy was administered.

We defined a case as having completed healing when a closed surgical site lacked secretion following the removal of suture materials. Delayed wound healing was defined by wound dehiscence and impaired wound healing following suture removal, but for which there was no need for reoperation. Larger wound dehiscence, necrosis, or infections that led to reoperation were defined as revision surgery.

\section{Follow-up care and prophylaxis}

There was no need to construct an anus praeter while using consistent perioperative bowel management, even when the PU was located in a perianal region. Bowel management consisted of defecation on the preoperative day, and the use of drug support whenever necessary. Patients with a daily defecation rhythm were administered Loperamide $2 \mathrm{mg}$ three times per day for 5 days, to reduce intestinal peristalsis. Intensive respiratory therapy, administered by 
Postoperative management after reconstructive flap surgery

Comply with:

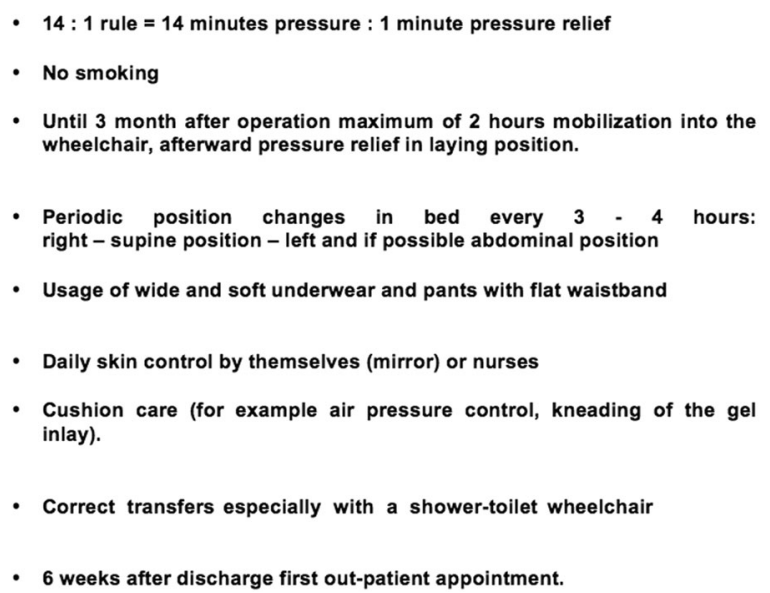

Fig. 2 Postoperative management after reconstructive flap surgery

therapists and Triflow usage $\left(\right.$ Triflo $^{\circledR}$ II, Hudson, Teleflex Medical, NC, USA) was regularly undertaken during the immobilisation time.

Up to the time of complete wound healing, mobilisation was performed for 1-3 days on the edge of the bed. Wheelchair mobilisation was performed with daily wound inspection, with an increase of $2 \times 30$ min every 3-5 days. Patients were discharged when a wheelchair mobilisation time of $2 \times 2 \mathrm{~h}$ was achieved.

The physiotherapists performed wheelchair pressure mapping assessments whenever a mobilisation time of $\geq 1 \mathrm{~h}$ was achieved; additionally, they reviewed all technical aids (i.e., wheelchairs, cushions, and mattresses). New aids were prescribed as needed.

All patients, as well as their relatives and personal nurses, were trained individually in measures to prevent further PUs. A standard information sheet was distributed to each individual (see Fig. 2).

\section{Clinical outcomes and follow-up}

Data regarding wound healing and treatment duration (admission $=>$ debridement $=>$ plastic surgical closur$\mathrm{e}=>$ mobilisation $=>$ discharge) were analysed. Following discharge, those who were treated were examined at an outpatient clinic for up to 3 years without regular intervals.

\section{Treatment-associated complications}

All treatment-associated complications during the hospital stay were documented. Recurrent PUs in the area of the surgical flap were recorded in the course of the follow-up examinations.

\section{Data collection}

Data pertaining to routine clinical examination upon admission, laboratory results (CC-reactive protein, leucocytes), microbiological wound swab results, and preoperative radiological findings were documented in a database. On discharge day, additional parameters were collected retrospectively. The raw data of this study are available from the authors by request.

\section{Statistical analysis}

Statistical analysis was performed using SPSS Statistics ${ }^{\odot}$ Version 23 (IBM, Armonk, NY, USA). Categorical variables are expressed as frequencies and percentages $(n, \%)$, and continuous variables as mean and standard deviation $(m, \mathrm{SD})$ values. Analysis of variance was performed for risk analyses.

\section{Results}

Baseline characteristics of the study participants are shown in Table 1.

The mean time since SCI was $19 \pm 13$ years. All patients presented a total of 63 PUs.

\section{Operative and perioperative management}

We performed a primary closure with the first debridement in two PUs (3\%), as there were clean wound conditions. In $38(60 \%)$ PUs, the plastic surgical closure was performed after one debridement. Further debridements were necessary in 23 (37\%) PUs.

Following debridement, 36 (57\%) PUs were treated with negative pressure wound dressings; in another $27(43 \%)$, wound irrigation and dressings with Lavanid ${ }^{\circledR}$ were applied. When comparing the total hospital length of stay of the negative pressure wound therapy (NPWT), a mean of 102 \pm 41 days vs. $92 \pm 37$ days was found for the group with Lavanid $^{\circledR}$ dressings.

The first debridement was performed $6 \pm 7$ days after admission, followed by a second procedure (i.e., debridement or plastic surgical closure) after $14 \pm 8$ days. If necessary, a third procedure was performed after a mean of $14 \pm 13$ days, and a fourth after $29 \pm 31$ days (i.e., further debridement or closure).

The time from admission to plastic surgical closure of PU was, on average, $25 \pm 15$ days for patients with one PU, $40 \pm 25$ days with two PUs, and $48 \pm 30$ days for those with more than two PUs. Following each definitive closing procedure, the Redon drains were removed, after $10 \pm 5$ days. 
Table 1 Participant characteristics

\begin{tabular}{ll}
\hline Number of flaps $n(\%)$ & $63(100)$ \\
Sacral area & $14(22)$ \\
Ischial area & $37(59)$ \\
Trochanteric area & $12(19)$ \\
Number of PUs per patient & \\
1 PU & $35(75)$ \\
2 PUs & $9(19)$ \\
2 PUs & $3(6)$ \\
Spinal cord lesion $(n=47$ patients $)$ & \\
Paraplegia & $29(62)$ \\
Tetraplegia & $18(38)$ \\
ASIA impairment scale score $(n=47)$ & \\
AIS A $n(\%)$ & $31(66)$ \\
AIS B $n(\%)$ & $9(19)$ \\
AIS C $n(\%)$ & $6(13)$ \\
AIS D $n(\%)$ & $1(2)$ \\
Gender $(n=47$ patients $)$ & \\
Female $n(\%)$ & $9(19)$ \\
Male $n(\%)$ & $38(81)$ \\
Age (range) in years $(n=47$ patients $)$ & $18-87$ \\
Mean in years & $51.4 \pm 16$ \\
Time since injury (range) in years $(n=47$ patients) & $1-47$ \\
Mean in years & $18.9 \pm 13$ \\
\hline
\end{tabular}

Prior to PU surgery, a terminal colostomy was performed in one patient (2\%) due to acute sigma diverticulitis. Three more patients already presented with a colostomy upon admission.

\section{Clinical outcomes, treatment-associated complications, and follow-up}

Wound healing was complete after a mean of $35 \pm 22$ days following the surgical closing procedure. Among all patients, the average length of stay was $100 \pm 36$ days (see Fig. 3).

There was postoperative wound healing without complications in $24(51 \%)$ patients. In $18(38 \%)$ patients, we encountered delayed wound healing, with there being a need for further surgery in five (11\%) cases (see Table 2). The use of revision surgery correlated with a longer time until wheelchair mobilisation and until discharge.

No risk factors (i.e., gender, PU localisation, AIS status, cause of paralysis, occurrence of pneumonia, or number of PUs) were found to significantly influence time to mobilisation or the total length of hospital stay.

The men with SCI showed statistically significantly more postoperative complications (i.e., delayed wound healing and revision surgery; $p=0.012$ ). Additionally, having an AIS A status was associated with a higher complication rate $(p=0.025)$.
We found a total of 142 pathogens in the microbiological swabs of all 63 PUs. The bacterial spectrum is summarised in terms of seven subgroups (see Table 3 ).

Pneumonia, diagnosed per CDC criteria, had developed in four $(11 \%)$ patients (25\% of all those with tetraplegia). This prompted treatment with antibiotics in all four patients.

During the follow-up period (which featured a mean observation time of $3 \pm 1$ years; range $1-5$ years), recurrence was documented in the former PU area in six (17\%) individuals. Of these, five appeared in the ischial area, and one in the trochanteric area.

\section{Discussion}

When discussing efficacy of treatment for this frequently occurring and expensive complication in people with SCI $[13,29]$, a cohort study is the first step to obtaining evidence regarding the various intervention components and outcome parameters, and how they relate to complication and recurrence rates [8]. Following the recommendation of a plastic surgical approach in treating grade IV PUs $[1,2,4$, $12,13]$, we achieved successful treatment and closure prior to discharge, unlike other cohorts [22].

To ensure the efficacy of a multimodal therapy regime, therapies used to treat grade IV PUs require interdisciplinary collaboration, and they should therefore be performed in centres that specialise in both the treatment of patients with SCI and the performance of plastic surgical procedures. Furthermore, certain aspects were standardised and integrated into the therapy regime and we believe they should be regularly implemented. These included the optimisation of nutrition with protein-enriched food supplements [2]; the provision of patient education; the development of strategies by to help prevent PUs; the supply of suitable technical aids (e.g., wheelchairs, cushions, and mattresses) [30]; and the development of urinary bladder and bowel management strategies by which to reduce the risk of incontinence [11,31].

One of the most frequently discussed aspects in the complex treatment of deep PUs in patients with SCI is postsurgical immobilisation time. For our treatment approach, we applied the standard of 21 days, and adopted it in cases of postsurgical complication. The mean duration of treatment for the PUs from the time of admission to discharge was 100 days; this was influenced by the number of lesions. The aim was to ensure the healing of all tissue layers $[1,3,4]$; in addition, there was the aim of preventing frequent paralysis-associated complications (e.g., pneumonia and depression) through the use of early mobilisation via wheelchair [24-26].

For the group treated with NPWT, time to mobilisation in the wheelchair was found to be longer than that of the 
Fig. 3 Mean length of hospital stay in days for patients depending by the number of PUs

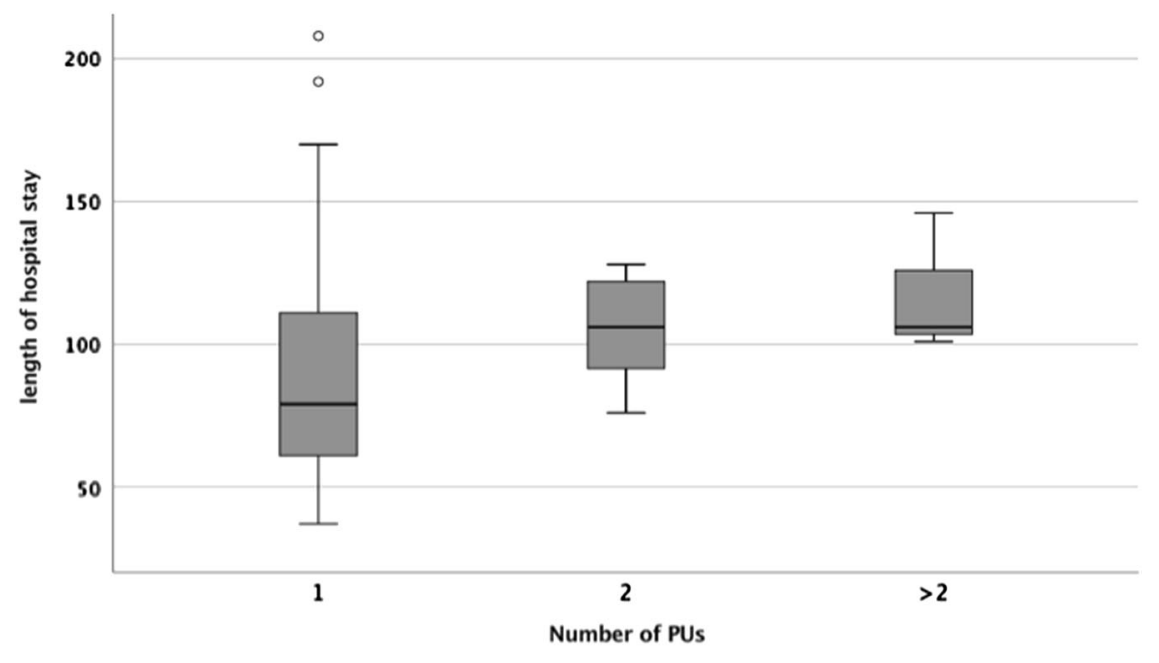

Table 2 Duration in days from first surgical closure procedure until mobilisation into the wheelchair by wound healing and number of PUs in all patients $(n=47)$

\begin{tabular}{|c|c|c|c|}
\hline & $\begin{array}{l}\text { Regular wound } \\
\text { healing }\end{array}$ & $\begin{array}{l}\text { Delayed wound } \\
\text { healing }\end{array}$ & $\begin{array}{l}\text { Revision } \\
\text { surgery }\end{array}$ \\
\hline \multicolumn{4}{|c|}{ All patients } \\
\hline $\begin{array}{l}52 \pm 29 \\
(n=47)\end{array}$ & $35 \pm 18(n=24)$ & $56 \pm 25(n=18)$ & $\begin{array}{l}100 \pm 20(n= \\
5)\end{array}$ \\
\hline \multicolumn{4}{|c|}{ Patients with one PU } \\
\hline $\begin{array}{l}47 \pm 29 \\
(n=35)\end{array}$ & $28 \pm 9(n=19)$ & $60 \pm 25(n=14)$ & $\begin{array}{l}108 \pm 33(n= \\
2)\end{array}$ \\
\hline \multicolumn{4}{|c|}{ Patients with two PUs } \\
\hline $\begin{array}{l}52 \pm 23 \\
(n=9)\end{array}$ & $65 \pm 19(n=4)$ & $40 \pm 22(n=4)$ & $92(n=1)$ \\
\hline \multicolumn{4}{|c|}{ Patients with $>2$ PUs } \\
\hline $\begin{array}{l}80 \pm 45 \\
(n=3)\end{array}$ & $48(n=1)$ & - & $97 \pm 23(n=2)$ \\
\hline
\end{tabular}

group treated with Lavanid ${ }^{\circledR}$ therapy, without influencing the total length of hospital stay. These results were compared to those of an earlier multicenter study with 68 patients with $\mathrm{III}^{\circ}$ and $\mathrm{IV}^{\circ} \mathrm{PUs}$, in which there were no significant differences in the healing rates of patients treated with NPWT vs. open wound healing [32]. Consequently, the selection of NPWT therapy in the complex treatment approach might be driven by reasons such as practicality, or that they are less time-consuming or less pain-inducing. Given the observational nature of this study, the results need to be interpreted with caution.

The literature reports complication and reoperation rates of 28-36 and $16 \%$, respectively $[1,13,33]$. In our sample, the rate of delayed wound healing was $38 \%$, and the reoperation rate was $10 \%$. In a slightly different population with $59 \%$ having flap surgery and $41 \%$ having mesh-grafts and debridements, complications occurred in $10.2 \%$ of cases, and

Table 3 Microbiological findings for all regions with $n=142$ identified pathogens

\begin{tabular}{|c|c|c|c|c|}
\hline & $\begin{array}{l}\text { Ischial region } \\
(n=83)\end{array}$ & $\begin{array}{l}\text { Sacral region } \\
(n=37)\end{array}$ & $\begin{array}{l}\text { Trochanteric region }(n \\
=22)\end{array}$ & $\begin{array}{l}\text { All locations ( } n \\
=142)\end{array}$ \\
\hline Staphylococcus $($ gram + ) & $16(19 \%)$ & $6(16 \%)$ & $6(27 \%)$ & $28(20 \%)$ \\
\hline Streptococus (gram-) & $10(12 \%)$ & $6(16 \%)$ & $2(9 \%)$ & $18(13 \%)$ \\
\hline Enterobacteriales (gram-) & $32(38 \%)$ & $10(28 \%)$ & $7(32 \%)$ & $49(35 \%)$ \\
\hline Enterococcus (gram-) & $9(11 \%)$ & $0(0 \%)$ & $0(0 \%)$ & $9(6 \%)$ \\
\hline Pseudomonas (gram-) & $8(10 \%)$ & $2(5 \%)$ & $4(18 \%)$ & $14(10 \%)$ \\
\hline $\begin{array}{l}\text { Anaerobs (obligate and } \\
\text { facultative) }\end{array}$ & $5(6 \%)$ & $9(24 \%)$ & $0(0 \%)$ & $14(10 \%)$ \\
\hline Multiresistent pathogens & $3(4 \%)$ & $4(11 \%)$ & $3(14 \%)$ & $10(7 \%)$ \\
\hline \multicolumn{5}{|l|}{ Number of pathogens } \\
\hline 1 pathogen & $8(22 \%)$ & $3(21 \%)$ & $3(23 \%)$ & $14(22 \%)$ \\
\hline 2 pathogens & $13(35 \%)$ & $6(43 \%)$ & $8(69 \%)$ & $27(43 \%)$ \\
\hline$>2$ pathogens & $16(43 \%)$ & $5(36 \%)$ & $1(8 \%)$ & $22(35 \%)$ \\
\hline
\end{tabular}


Table 4 Outcome and follow-up analysis of all performed flaps and comparison to the literature

\begin{tabular}{|c|c|c|c|c|c|c|c|c|c|}
\hline & $\begin{array}{l}\text { Time of } \\
\text { surgery }\end{array}$ & Site of PU & Total & Dehiscence $(\%)$ & Reoperation (\%) & $\begin{array}{l}\mathrm{F} \text { to } \mathrm{H} \\
(\mathrm{d})^{\mathrm{a}}\end{array}$ & $\begin{array}{l}\text { Follow-up } \\
\text { (years) }\end{array}$ & $\begin{array}{l}\text { Recurrence rate } \\
(\%)\end{array}$ & $\begin{array}{l}\mathrm{F} \text { to } \mathrm{R} \\
\text { (d) }\end{array}$ \\
\hline \multirow{4}{*}{$\begin{array}{l}\text { Schryvers et al. } \\
\text { [1] }\end{array}$} & \multirow[t]{4}{*}{ 1976-1996 } & Sacral & 7 & 71 & & 45 & & 14 & 371 \\
\hline & & Ischial & 43 & 40 & & 64 & & 33 & 572 \\
\hline & & Trochanteric & 43 & 40 & & 106 & & 16 & 934 \\
\hline & & Total & 93 & 42 & 11 & 82 & & 24 & 697 \\
\hline \multirow[t]{4}{*}{ Ljung et al. [34] } & \multirow[t]{4}{*}{$2002-2007$} & Sacral & 7 & & & & & & \\
\hline & & Ischial & 45 & & & & & & \\
\hline & & Trochanteric & 8 & & & & & & \\
\hline & & Total & 60 & $\mathrm{n} / \mathrm{a}$ & 6 & & $3 / 10$ & $11 / 38$ & $\mathrm{n} / \mathrm{a}$ \\
\hline \multirow[t]{4}{*}{ Our data } & \multirow[t]{4}{*}{ 2008-2012 } & Sacral & 14 & 36 & & 33 & & 0 & - \\
\hline & & Ischial & 37 & 35 & & 36 & & 14 & 300 \\
\hline & & Trochanteric & 12 & 33 & & 29 & & 8 & 534 \\
\hline & & Total & 63 & 35 & 8 & 34 & 3 & 10 & 358 \\
\hline
\end{tabular}

${ }^{a} \mathrm{~F}$ to $\mathrm{H}$, date of flap surgery to date of healing

${ }^{\mathrm{b}} \mathrm{F}$ to $\mathrm{R}$, date of flap surgery to date of recurrence

reoperation was needed in $2.6 \%$ of cases [4]. With different patient and PU characteristics, comparisons between the literature and the current sample are not easily done.

In the overall sample, we found there to be a low recurrence rate (i.e., 15\%). We also found there to be a higher rate of recurrence in flaps over the ischial area; additionally, these patients showed a significant higher number of postoperative complications. A comparison of postoperative complications and recurrence rates with the study of Schryvers et al. and Ljung et al. is presented in Table 4. The concept of Ljung et al. consists of 7-11 days in the surgical department before discharge to a rehabilitation facility. They describe two major complications with a lethal outcome in one patient. Therefore, it might be beneficial that the surgical treatment as well as the further rehabilitation is performed in a specialised SCI centre to cope with major complications [1,34].

Based on the anatomical nature of the ischial area, a 90-degree flexion in the hip leads to a massive increase in length and pressure in the tissue in the surgical field. As a preventative measure, fixation of the hip joint in an extended position can be useful, and a longer immobilisation period for flaps over the ischial area (i.e., of up to 4 weeks) could reduce recurrence rates. The literature reports recurrence rates of 3-61\% across very inhomogeneous patient cohorts and a large variety of operative strategies, making comparisons difficult [2, 4, 35-37]. In a systematic literature analysis [36], no difference was found among the recurrence rates, depending on the operation techniques used (i.e., musculocutaneous, fasciocutaneous, perforator-based flaps). Furthermore, differences in PU localisation led to no significant differences in the recurrence rates [33].
Many different aspects are possible risk factors for PU occurrence. Age, lower level of education, a complete spinal lesion, and malnutrition have been identified as risk factors [1, 38, 39]; male gender has also been considered a risk factor [40, 41]. We found that having an AIS A score and being male were risk factors for postoperative complications (i.e., delayed wound healing and reoperation). The higher risk among AIS A patients may stem from sensory complete lesions and the absence of perception of prolonged pressure exposition. The higher complication rate among men with SCI might have different explanations and require further research. For a pathology in which treatment depends on patient cooperation (i.e., for nutrition, positioning in the bed and wheelchair, and prophylaxis), strategies to increase compliance are necessary [8, 23, 38]. Therefore, awareness of the importance of pressure relief needs to be addressed through the provision of effective outpatient nursing services and the education of the patients' relatives prior to discharge.

The occurrence of pneumonia in our patients seemed to result from immobilisation during treatment. The prevention is very important in our opinion to reduce the risk of treatment-associated complications. Therefore, prevention strategies should involve clearing and inflating the lungs regularly.

In our sample, we encountered a broad bacterial spectrum. As the patients' PUs were largely in the perianal region, we mostly recorded gram-negative species. Since there are no established guidelines, we considered the operative PU treatment as septic surgery. For this reason, we administered antibiotic treatment for 14 days or even longer if no complete wound healing had been achieved. Given the retrospective design of this study, the effects of this treatment cannot be 
evaluated. In further studies, risk factors associated with impaired wound healing, as well as the need for and duration of antibiotic treatment, should be investigated.

\section{Study limitations}

A number of features of this study serve as limitations; these include the small sample size, the use of retrospective data, and its two-centre design.

The retrospective approach we used is not ideal for supporting or negating any hypotheses; however, it is useful in identifying tendencies that can be further verified in future research. The retrospective design limits our analysis to routinely collected data.

Furthermore, the small number of patients in the subgroups leads to low statistical power. Certain psychosocial risk factors are known to be relevant for compliance during hospitalisation, but have not yet been regularly integrated in our treatment protocol, as either assessments or interventions; therefore, a number of important explanatory factors remain to be elucidated.

\section{Conclusion}

The treatment of grade IV PUs in patients with SCI is associated with high complication and recurrence rates. Our finding is that the therapeutic use of a multimodal treatment approach in a SCI centre might be associated with lower complication rates. Our findings suggest that treatment duration is dependent on PU localisation and number; and PUs of the ischial region tends to be accompanied by higher complication rates, given the nature of the anatomy in that region. To reduce the high occurrence of pneumonia-which tends to be associated with treatment-specific prevention measures should be established. Further analysis of PU and patient characteristics at baseline and the components of a complex treatment approach should be performed in a prospective multicenter study or clinical trial to garner evidence regarding efficacy.

\section{Compliance with ethical standards}

Conflict of interest The authors declare that they have no conflict of interest.

\section{References}

1. Schryvers OI, Stranc MF, Nance PW. Surgical treatment of pressure ulcers: 20-year experience. Arch Phys Med Rehabil. 2000;81:1556-62.

2. Rieger U, Scheufler O, Schmid D, Zweifel-Schlatter M, Kalbermatten D, Pierer G. Die sechs Behandlungsprinzipien des Basler
Dekubituskonzepts. Handchir Mikrochir Plast Chir. 2007;39:206-14.

3. Kruger EA, Pires M, Ngann Y, Sterling M, Rubayi S. Comprehensive management of pressure ulcers in spinal cord injury: current concepts and future trends. J Spinal Cord Med. 2013;36:572-85.

4. Srivastava A, Gupta A, Taly AB. Surgical management of pressure ulcers during inpatient neurologic rehabilitation: outcomes for patients with spinal cord disease. J Spinal Cord Med. 2009;32:125-31.

5. Stausberg J, Kiefer E. Classification of pressure ulcers: a systematic literature review. Stud Health Technol Inform. 2009;146:511-5.

6. National Pressure Ulcer Advisory Panel EPUAPaPP, Alliance PI. Prevention and treatment of pressure ulcers: quick reference guide. Perth: Cambridge Media; 2014.

7. Mak AF, Zhang M, Tam EW. Biomechanics of pressure ulcer in body tissues interacting with external forces during locomotion. Annu Rev Biomed Eng. 2010;12:29-53.

8. Chen Y, Devivo MJ, Jackson AB. Pressure ulcer prevalence in people with spinal cord injury: age-period-duration effects. Arch Phys Med Rehabil. 2005;86:1208-13.

9. Hartkopp A, Bronnum-Hansen H, Seidenschnur AM, BieringSorensen F. Survival and cause of death after traumatic spinal cord injury. A long-term epidemiological survey from Denmark. Spinal Cord. 1997;35:76-85.

10. Byrne DW, Salzberg CA. Major risk factors for pressure ulcers in the spinal cord disabled: a literature review. Spinal Cord. 1996;34:255-63.

11. Schubart JR, Hilgart M, Lyder C. Pressure ulcer prevention and management in spinal cord-injured adults: analysis of educational needs. Adv Skin Wound Care. 2008;21:322-9.

12. Sorensen JL, Jorgensen B, Gottrup F. Surgical treatment of pressure ulcers. Am J Surg. 2004;188:42-51.

13. Disa JJ, Carlton JM, Goldberg NH. Efficacy of operative cure in pressure sore patients. Plast Reconstr Surg. 1992;89: 272-8.

14. Sundell B, Pentti A, Langensiold A. Surgical treatment of pressure ulcers in paraplegics. Acta Orthop Scand. 1967;38:532-42.

15. Braver SD. Surgical treatment of decubitus ulcers in paraplegic patients. Ohio State Med J. 1968;64:582-5.

16. Foster RD, Anthony JP, Mathes SJ, Hoffman WY. Ischial pressure sore coverage: a rationale for flap selection. Br J Plast Surg. 1997;50:374-9.

17. Parkash S, Banerjee S. The total gluteus maximus rotation and other gluteus maximus musculocutaneous flaps in the treatment of pressure ulcers. Br J Plast Surg. 1986;39:66-71.

18. Mandrekas AD, Mastorakos DP. The management of decubitus ulcers by musculocutaneous flaps: a five-year experience. Ann Plast Surg. 1992;28:167-74.

19. Cope C, Barry P, Hassall M, Barnett R, Richards M, Vandervord J. V-Y advancement hamstring myocutaneous island flap repair of ischial pressure ulcers. Aust N Z J Surg. 1995;65: 412-6.

20. Paletta CE, Freedman B, Shehadi SI. The VY tensor fasciae latae musculocutaneous flap. Plast Reconstr Surg. 1989;83:852-7.

21. Nahai F. The tensor fascia lata flap. Clin Plast Surg. 1980;7: 51-6.

22. Guihan M, Bombardier CH. Potentially modifiable risk factors among veterans with spinal cord injury hospitalized for severe pressure ulcers: a descriptive study. J Spinal Cord Med. 2012;35:240-50.

23. Marin J, Nixon J, Gorecki C. A systematic review of risk factors for the development and recurrence of pressure ulcers in people with spinal cord injuries. Spinal Cord. 2013;51:522-7. 
24. Wettstein R, Tremp M, Baumberger M, Schaefer DJ, Kalbermatten DF. Local flap therapy for the treatment of pressure sore wounds. Int Wound J. 2015;12:572-6.

25. Lüscher NJ. Value of surgical treatment of decubitus ulcer in geriatric patients. Ther Umsch Rev Ther. 1991;48:341-6.

26. De Roche R. Störfall Decubitus-Handbuch zur gesundheitsökonomischen Bedeutung, Prävention, konservativen und chirurgischen Therapie. Rehab Basel. 2012;1:280.

27. Dellinger RP, Levy MM, Rhodes A, Annane D, Gerlach H, Opal SM, et al. Surviving Sepsis Campaign: international guidelines for management of severe sepsis and septic shock, 2012. Intensive Care Med. 2013;39:165-228.

28. Kondrup J, Rasmussen HH, Hamberg O, Stanga Z. Nutritional risk screening (NRS 2002): a new method based on an analysis of controlled clinical trials. Clin Nutr. 2003;22:321-36.

29. Devivo MJ. Epidemiology of traumatic spinal cord injury: trends and future implications. Spinal Cord. 2012;50:365-72.

30. Kato $\mathrm{H}$, Inoue $\mathrm{T}$, Torii $\mathrm{S}$. A new postoperative management scheme for preventing sacral pressure sores in patients with spinal cord injuries. Ann Plast Surg. 1998;40:39-43.

31. Wilczweski P, Grimm D, Gianakis A, Gill B, Sarver W, McNett M. Risk factors associated with pressure ulcer development in critically ill traumatic spinal cord injury patients. J Trauma Nurs. 2012;19:5-10.

32. Ho CH, Powell HL, Collins JF, Bauman WA, Spungen AM. Poor nutrition is a relative contraindication to negative pressure wound therapy for pressure ulcers: preliminary observations in patients with spinal cord injury. Adv Skin Wound Care. 2010;23: 508-16.
33. Foster RD, Anthony JP, Mathes SJ, Hoffman WY, Young D, Eshima I. Flap selection as a determinant of success in pressure sore coverage. Arch Surg. 1997;132:868-73.

34. Ljung AC, Stenius MC, Bjelak S, Lagergren JF. Surgery for pressure ulcers in spinal cord-injured patients following a structured treatment programme: a 10-year follow-up. Int Wound J. 2017;14:355-9.

35. Kierney PC, Engrav LH, Isik FF, Esselman PC, Cardenas DD, Rand RP. Results of 268 pressure sores in 158 patients managed jointly by plastic surgery and rehabilitation medicine. Plast Reconstr Surg. 1998;102:765-72.

36. Sameem M, Au M, Wood T, Farrokhyar F, Mahoney J. A systematic review of complication and recurrence rates of musculocutaneous, fasciocutaneous, and perforator-based flaps for treatment of pressure sores. Plast Reconstr Surg. 2012;130:67e-77e.

37. Tchanque-Fossuo CN, Kuzon WMJ. An evidence-based approach to pressure sores. Plast Reconstr Surg. 2011;127:932-9.

38. Coleman S, Gorecki C, Nelson EA, Closs SJ, Defloor T, Halfens $\mathrm{R}$, et al. Patient risk factors for pressure ulcer development: systematic review. Int J Nurs Stud. 2013;50:974-1003.

39. Ash D. An exploration of the occurrence of pressure ulcers in a British spinal injuries unit. J Clin Nurs. 2002;11:470-8.

40. Eslami V, Saadat S, Habibi Arejan R, Vaccaro AR, Ghodsi SM, Rahimi-Movaghar V. Factors associated with the development of pressure ulcers after spinal cord injury. Spinal Cord. 2012;50:899-903.

41. Rabadi MH, Vincent AS. Do vascular risk factors contribute to the prevalence of pressure ulcer in veterans with spinal cord injury? J Spinal Cord Med. 2013;34:46-51. 